\title{
ARTE, SOCIEDADE E A IMPORTÂNCIA DOS READY-MADES NA BIENAL DE SÃO PAULO
}

\author{
Leonardo Schabbach Oliveira* \\ Luísa Pinheiro**
}

Resumo: 0 presente artigo procura investigar as razões pelas quais se vê, na arte contemporânea, uma presença crescente de obras que refletem sobre a questão da autoria e também sobre os próprios fundamentos da obra de arte. Para tal, observa-se, na Bienal de São Paulo, a questão dos ready-mades e se busca, por meio disso, compreender melhor a relação entre arte, sociedade e filosofia, trazendo uma reflexão sobre como a visão da sociedade e dos indivíduos acerca da arte se modifica com o deslocamento de uma visão de projetos coletivos predominante na modernidade para uma visão individual de realidade presente no periodo pós-moderno.

Palavras-chave: Arte contemporânea. Bienal de São Paulo. Modernidade. Pós-modernidade. Pós-modernismo.

\section{INTRODUÇÃO}

A arte e a filosofia possuem uma relação íntima e intensa com a sociedade, modificando-se e transformando-se com ela. Ao mesmo tempo, ambas possuem a qualidade de também alterar a forma de os indivíduos pensarem e enxergarem o mundo, isto é, são, por isso, também capazes de questionar e transformar o âmbito social, como se vê constantemente no que se pode classificar como arte de vanguarda, no sentido específico de uma arte capaz de colocar em xeque tradições artísticas e sociais, fazendo os individuos refletirem criticamente sobre tais tradições e antecipando grandes mudanças sociais.

Desse modo, tem-se um cenário complexo em que arte, filosofia e sociedade estão interligadas e dialogam entre si, num processo constante e dialético de mudança. Por isso mesmo, olhar para a arte de um determinado periodo histórico é também compreender com mais profundidade a sociedade e os próprios pensamentos filosóficos daquele período. Não à toa, olhar para a chamada modernidade, em que se tem uma sociedade de projetos coletivos, pautada pela crença na verdade e na civilização, como aponta Zygmunt Bauman (1997) em 0 mal-estar da pós-modernidade, é perceber o consequente surgimento do realismo nas

\footnotetext{
* Doutor e Mestre em Comunicação e Cultura pela Universidade Federal do Rio de Janeiro (UFRJ). E-mail: leoschabbach@gmail.com

** Doutora em Educação, Artes e História da Cultura pela Universidade Presbiteriana Mackenzie. Mestra em Artes Cênicas pela Universidade Federal do Estado do Rio de Janeiro (UNIRIO). Roteirista.E-mail: lu_pinheiro100@hotmail.com
} 
artes e na literatura, por exemplo, que se propunha a ser extremamente racional e científico, que procurava por isso ser uma espécie de réplica verdadeira - e não romantizada, como em períodos anteriores - da própria realidade, seguindo, por isso, justamente a crença em uma busca pela Verdade (em maiúsculo aqui para indicá-la como única e imutável, "verdadeira", portanto) ocorrida no período.

De modo semelhante, é interessante observar na própria arte o questionamento subsequente de tais tradições artísticas por meio do modernismo, que buscava justamente romper com tais tradições e também antecipava - além de buscar por - grandes mudanças sociais, que viriam a se radicalizar, algumas décadas depois, com o advento do que se pode chamar de pós-modernidade (ou modernidade tardia, como alguns poderiam colocar) e, no caso das artes, com o pós-modernismo ou a contemporaneidade.

Por esses motivos, considera-se extremamente importante olhar para os movimentos artísticos e, por meio deles, compreender melhor também a sociedade contemporânea e a sua forma de perceber o mundo. Torna-se interessante olhar para arte e perceber com mais profundidade a sua relação com o social - e como sociedade, arte e filosofia se transformam juntas. Logo, observar um evento como a Bienal de São Paulo e a presença de determinadas expressões artísticas se torna, portanto, essencial para se compreender melhor também a sociedade contemporânea.

Buscar observar e compreender tais expressões artísticas é, por isso, compreender também as mudanças sociais e filosóficas e a sua íntima ligação com essas expressões. $E_{1}$ nesse contexto, como será explicitado no presente artigo, a forte presença dos chamados ready- mades chamou a atenção, por trazer profundas reflexões a respeito da questão da autoria e de como ela se comunica diretamente com um período histórico que se irá classificar aqui como pós-modernidade. Desse modo, o que se propõe é olhar para a Bienal de São Paulo e para os ready-mades pensando em como isso se relaciona com os questionamentos e com o estilo de vida pós-moderno. Assim, tornar-se-á possível explicitar como o questionamento da autoria, extremamente presente na arte contemporânea, está intimamente ligado a uma forma diferente de se olhar para o mundo surgida na pós-modernidade.

\section{PÓS-MODERNIDADE E PÓS-MODERNISMO}

Naturalmente, como se falou dos dois diferentes conceitos aqui, é necessário explicitar a sua diferenciação para que seja possivel mostrar, inclusive, como a maneira de perceber o mundo do indivíduo da pós-modernidade possui grande influência na forma de se fazer arte no pós-modernismo ou na contemporaneidade. No entanto, como bem aponta o filósofo Terry Eagleton (1996, p. 3): 
A palavra pós-modernismo refere-se em geral a uma forma de cultura contemporânea, enquanto o termo pós-modernidade alude a um periodo histórico específico. Pós-modernidade é uma linha de pensamento que questiona as noções clássicas de verdade, razão, identidade e objetividade, a idéia de progresso ou emancipação universal, os sistemas únicos, as grandes narrativas ou os fundamentos definitivos de explicação. Contrariando essas normas do iluminismo, vê o mundo como contingente, gratuito, diverso, instável, imprevisivel, um conjunto de culturas ou interpretações desunificadas gerando um certo grau de ceticismo em relação à objetividade da verdade, da história e das normas, em relação às idiossincrasias e à coerência de identidades. Essa maneira de ver, como sustentam alguns, baseia-se em circunstâncias concretas: ela emerge da mudança histórica ocorrida no Ocidente para uma nova forma de capitalismo - para o mundo efêmero e descentralizado da tecnologia, do consumismo e da indústria cultural, no qual as indústrias de serviços, finanças e informação triunfam sobre a produção tradicional, e a política clássica de classes cede terreno a uma série difusa de "políticas de identidade". Pós-modernismo é um estilo de cultura que reflete um pouco essa mudança memorável por meio de uma arte superficial, descentrada, infundada, auto-reflexiva, divertida, caudatária, eclética e pluralista, que obscurece as fronteiras entre a cultura "elitista" e a cultura "popular", bem como entre a arte e a experiência cotidiana. 0 quão dominante ou disseminada se mostra essa cultura - se tem acolhimento geral ou constitui apenas um campo restrito da vida contemporânea - é objeto de controvérsia.

Ou seja, o trecho indicado mostra essa separação entre pós-modernidade e pós-modernismo. Vale lembrar, no entanto, que a classificação dada por Eagleton (1996) em relação ao pós-modernismo como cultura e arte, que possui um sentido negativo, não serve ao propósito deste artigo, uma vez que aqui se busca justamente observar a arte do pós-modernismo (ou contemporânea) compreendendo como ela é fruto de um período histórico e filosófico determinado (a pós-modernidade) e como se comunica, portanto, com ele, trazendo por isso todo o seu valor crítico e reflexivo. Todavia, o trecho mostra com clareza a separação entre um movimento artístico e cultural e um movimento filosófico delineado dentro de um determinado período histórico, a pós-modernidade, que coloca as questões fundamentais em xeque, como a própria questão da verdade, das identidades e até mesmo da história.

Nesse sentido, tem-se uma pós-modernidade, conforme apontada pelo filósofo Jean Baudrillard (1991, p. 9), que "já não é a do real, nem a da verdade, a era da simulação inicia-se, pois, com uma liquidação de todos os referencias". Isto é, um período em que a própria verdade e as grandes narrativas se perdem e são colocadas em dúvida, são questionadas e se esvaziam, algo que se diferencia radicalmente (como será visto ao longo do artigo) da modernidade, que buscava, por meio da ciência, da história e, como consequência, das grandes narrativas e paradigmas, desvelar uma Verdade (absoluta). 
Isso já nos remete diretamente, portanto, à questão da autoria. Afinal, o autor nada mais é, em uma obra, por uma visão moderna, do que o seu fundamento, a sua razão de ser e de existir, a fonte na qual se pode compreender o que aquela obra realmente significa. $E_{1}$ com a transição de uma modernidade para a contemporaneidade, isso também será, portanto, questionado. Quando Marcel Duchamp, em 1917, décadas antes da eclosão do pós-modernismo e da pós-modernidade, uma vez mais revelando o caráter de vanguarda que a arte pode ter, cria a sua obra $A$ fonte e coloca um mictório em exposição em um museu, o que ele faz é justamente colocar em questão os fundamentos do que seria uma obra de arte e o seu autor. Afinal, seria aquilo arte? E quem seria o autor? Trata-se não de uma escultura feita por um determinado artista, mas de um objeto fabricado industrialmente.

Deveríamos realmente o classificar como arte então? E, se for, qual será o seu fundamento? Qual será o seu autor? Seria quem fabricou o mictório industrialmente? Ou Duchamp ao cunhar um conceito? Seria o museu que o expôs? Ou cada um dos indivíduos que se depara com aquela obra retira dela as próprias conclusões? Enfim, tal ato, além de criar os chamados ready-mades, traz inúmeras questões a respeito dos fundamentos do que seria uma obra de arte. E isso em muito antecipou o que iria acontecer no pós-modernismo (ou arte contemporânea, expressão que no presente artigo se considera mais adequada), como se verá adiante. E colocou em discussão, naturalmente, a questão da autoria.

\section{AUTORIA, ARTE CONTEMPORÂNEA E OS READY-MADES}

A noção de autoria constitui um momento crucial de individualização na história das artes e do conhecimento. A relação de uma obra com seu autor e a maneira como ela aponta diretamente para essa figura que lhe é exterior são características fundamentais para os estudos críticos literários ocidentais. Em diferentes correntes interpretativas - como as de cunho cientificistas do século XIX -, as obras são explicadas, entre outros fatores, principalmente por quem as produziu. Tal análise considera que, por meio da alegoria da ficção, há a voz de apenas uma pessoa, o autor, que, com autoridade, exporia suas confidências e verdades de modo mais ou menos oculto. Sob essa perspectiva, o sentido profundo de uma obra sempre é dado pelo autor.

Porém, em diversos estudos, teóricos contemporâneos como Foucault, Barthes e Perrone-Moisés contestam a primazia do autor, afirmando que a atividade criativa tem especificidades que colocam em xeque qualquer perspectiva estável quanto à questão da autoria. A partir do século XX, em consonância com o desenvolvimento crescente de novas tecnologias, da constante virtualização das relações e das novas dinâmicas socioculturais, a relação artista-obra é radicalmente questionada.

Para Barthes (1988), o autor é um personagem moderno, produzido pela sociedade no fim da Idade Média com a descoberta da possibilidade de prestígio social do indivíduo. A partir 
desse momento, têm início as pesquisas de autenticidade e atribuição de autoria que, por meio de uma lógica capitalista, unem pessoa e obra, criando uma imagem da literatura, na cultura corrente, centrada na figura do autor, em seus gostos, suas paixões, seus traços biográficos e afins.

Se na Antiguidade inúmeras obras de arte circulavam sem qualquer reivindicação de autoria, a partir do Renascimento e de sua proposta de valorização do homem como aquele que é dotado de razão, a subjetividade do produtor entra em jogo como aquela capaz de dar sentido e características próprias ao objeto artístico. Assim, torna-se possível perceber que a função autor não é exercida de maneira universal e atemporal em todas as obras e discursos.

$\mathrm{Na}$ literatura, inclusive, houve um tempo em que as epopeias, tragédias e diversos outros textos literários eram postos em circulação sem que houvesse atribuição de autoria, enquanto os discursos científicos só mantinham valor caso apresentassem o nome de seus autores. A partir dos séculos XVII e XVIII, houve uma inversão. Discursos científicos passaram a ser válidos ainda que no anonimato. E textos literários ganharam a obrigatoriedade de apresentar a função autor.

Segundo Foucault (2011), São Jerônimo fornece quatro critérios de autenticidade de uma obra em relação à autoria, os quais, de acordo com o filósofo francês, ainda definem as modalidades segundo as quais a crítica faz atuar a função autor. Para São Jerônimo:

Se, entre vários livros atribuidos a um autor, um é inferior aos outros, é preciso retirá-lo da lista de suas obras; [...] além disso, se certos textos estão em contradição de doutrina com as outras obras de um autor [...] é preciso igualmente excluir as obras que estão escritas em um estilo diferente, com palavras e formas de expressão não encontradas usualmente sob a pena do escritor; [...] devem, enfim, ser considerados como interpolados os textos que se referem a acontecimentos ou que citam personagens posteriores à morte do autor (FOUCAULT, 2011, p. 17-18).

Dessa forma, o autor é definido como certo nivel constante de valor, como dotado de coerência conceitual e como aquele que possui unidade estilística. É ainda tido como momento histórico definido, bem como vértice de determinados acontecimentos.

Logo, ainda de acordo com o teórico, a atribuição de autoria não é um simples elemento de um discurso. Ela exerce certo papel, assegurando uma função classificatória, já que é capaz de juntar diversas obras e delimitá-las, como sendo pertencentes a um mesmo grupo. 0 nome do autor é capaz ainda de aferir um modo de ser do discurso que sua produção carrega. Desse modo, tal atribuição aparece como um modo de existência e de circulação de determinados discursos no interior de uma sociedade.

Tal qual a literatura, a partir do realismo, as obras de arte igualmente passam a ter em seu autor a reunião de seu sentido e de suas proposições. Se pinturas rupestres ou diversos obje- 
tos artísticos ligados, por exemplo, à religião têm autoria desconhecida, com o movimento realista esta passa a ser sinônimo de status. É no periodo compreendido pelas primeiras vanguardas que tal estrutura começa a ser questionada, já que conceitos como unicidade da obra de arte, artesania e originalidade são radicalmente problematizados.

Tal questão, porém, não necessariamente retira, nas artes, a importância da figura do autor, mas desloca suas atribuições. Se antes o autor de uma obra necessariamente dava as pinceladas sobre uma tela ou modelava uma escultura, esse novo autor não mais é necessariamente responsável pela execução física da obra, mas pela construção de um discurso artístico, ressignificando e muitas vezes politizando objetos de usos absolutamente cotidianos.

Um dos casos mais emblemáticos e já citado pelo presente artigo é a obra $A$ fonte, de Marcel Duchamp. É Duchamp, inclusive, que cunha o conceito de ready-mades, igualmente fundamental para se compreender o deslocamento da noção de autoria dentro da arte contemporânea. Os ready-mades abalam a teoria da arte ao permitirem que um objeto artístico não mais tenha que se diferir formalmente de um outro comum. Como se entre dois objetos de mesma origem e aparência um pudesse pertencer ao universo das artes e o outro não.

Comungando com o advento da reprodutibilidade técnica apontada por Walter Benjamin (1987, p. 186), nos ready-mades a aura da obra de arte é questionada, já que "a reprodutibilidade técnica da obra de arte emancipa-a, pela primeira vez na história, de sua existência parasitária no ritual. [...] Em vez de fundar-se no ritual, ela passa a fundar-se em outra praxis: na política". Dessa forma, ocorre uma mudança não apenas na relação da obra de arte com seu idealizador, mas também com o público que a frui.

A primeira definição de ready-mades fornecida por Duchamp afirmava que tais objetos eram simplesmente "um objeto comum promovido a objeto de arte através da escolha do artista" (BRETON; ELUARD, 1938, p. 23, tradução nossa.). Assim, o fazer artístico se liga à escolha e à criação de diálogos mais do que à manipulação artesanal de um material. Duchamp alarga, então, os limites do campo das artes revolucionando o panorama artístico e relativizando a importância do próprio objeto de arte.

Além dos ready-mades, inúmeras outras manifestações artísticas contemporâneas questionam e deslocam as noções correntes em relação à autoria, como as performances. Porém, este artigo vai se limitar a investigar mais profundamente o legado de Marcel Duchamp e algumas relações específicas que suas obras e proposições estabeleceram em determinadas edições da Bienal de São Paulo.

\section{READY-MADES E A BIENAL DE SÃO PAULO}

0 legado de Marcel Duchamp é tamanho que seria impossivel querer mapear todas as vezes em que um ready-made esteve presente em uma bienal. Por isso, alguns casos emble- 
máticos foram selecionados para este trabalho cujo objetivo é abordar aspectos da $33^{\mathrm{a}}$ Bienal de São Paulo que ocorreu em 2018.

Antes de comentar algumas obras dessa Bienal, é preciso recordar que a 19a edição da mostra, realizada no ano de 1987 e intitulada Utopias versus realidade, teve uma sala exclusivamente dedicada a obras de Marcel Duchamp.

Figura 1 Obras de Marcel Duchamp

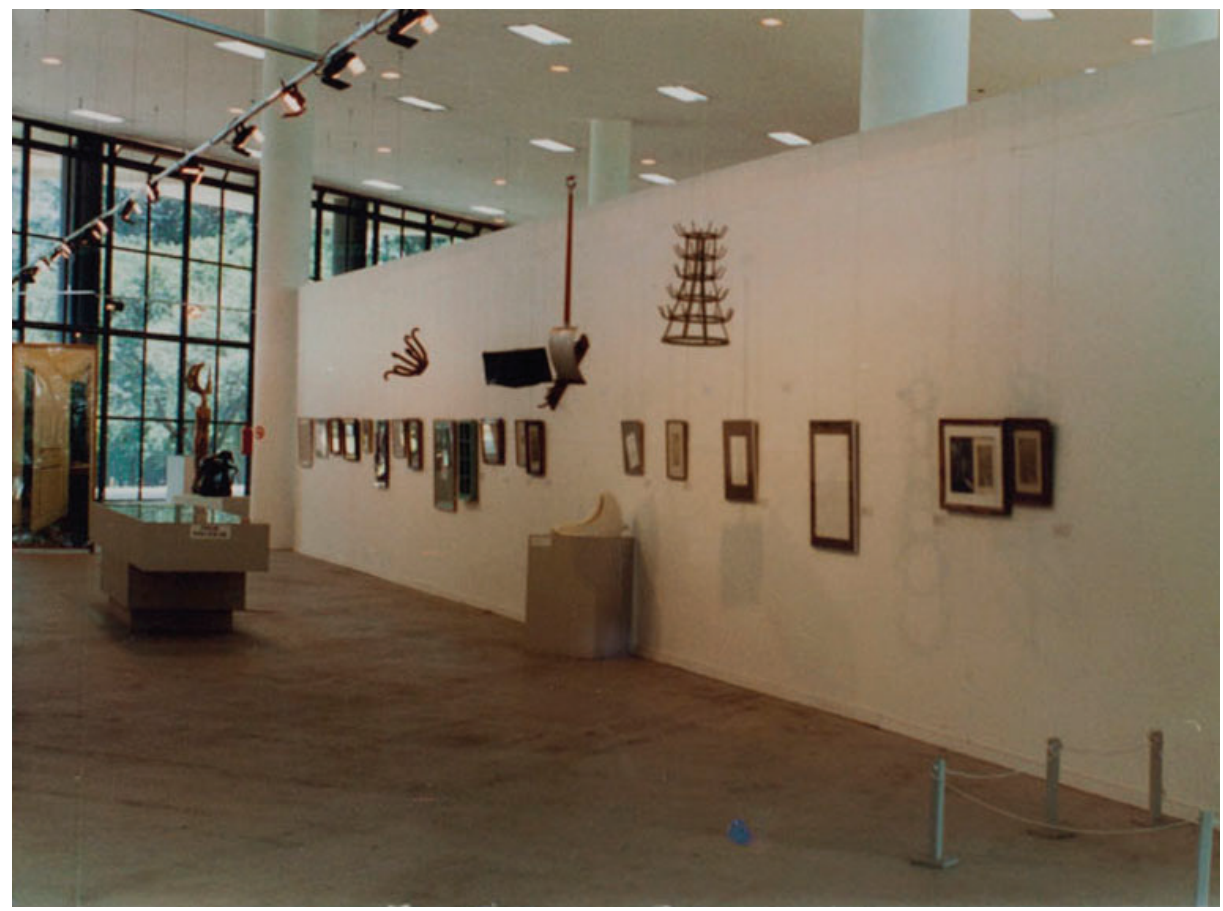

Fonte: Foto de Guimar Morelo.

Ali estavam presentes, junto a fotos e desenhos, diversos ready-mades, como o próprio mictório intitulado $A$ fonte e uma pá pendurada no alto da sala. Além da sala destinada a Duchamp, muitos outros artistas, da mesma edição e de outras, dedicaram-se a encontrar novos significados para objetos industrializados com o intuito de garantir-lhes artisticidade.

A 33a Bienal, intitulada Afinidades afetivas, igualmente trouxe diversas obras que permitem ver o deslocamento e a politização de objetos antes ordinários no universo artístico. John Miller, por exemplo, colocou em evidência uma série de três armários tipicamente usados para arquivar papéis e documentos em escritórios. Ao conferir status de obra de arte aos objetos, o autor monumentalizou a alienação, o trabalho e o tempo, conforme explicita em sua definição da obra. 
Figura 2 A alienação, o trabalho e o tempo na obra de John Miller

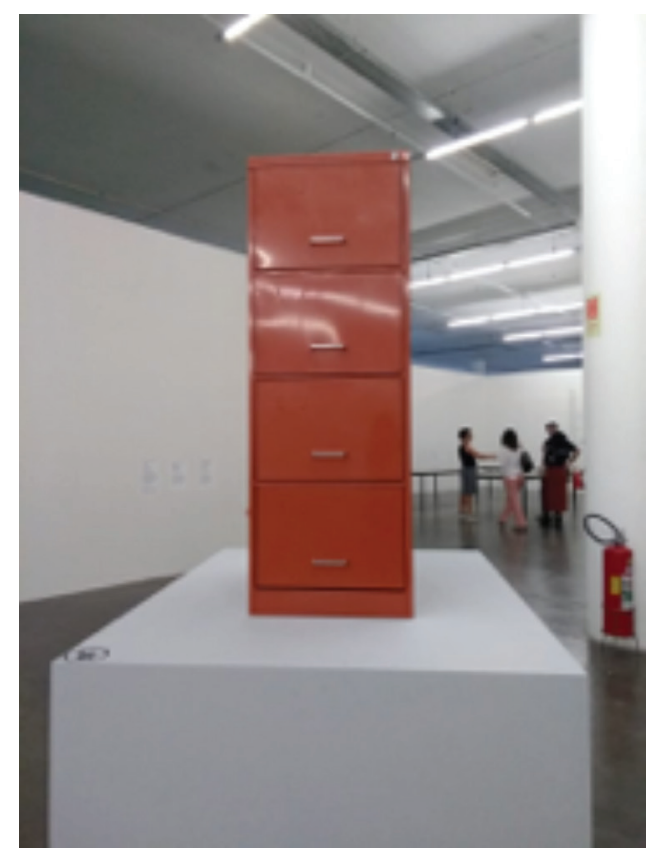

Fonte: Foto de Luisa Pinheiro.

Oliver Laric, na mesma bienal, coloca em sua obra, entre a exibição de dois vídeos, um manequim composto por diversas partes, entre opacas e transparentes. Ao manipular peças provavelmente já pré-fabricadas atribuindo-Ihes, por meio de sua capacidade crítico-artística, novas capacidades de significação, o autor reforça uma vez mais que o lugar da obra de arte igualmente é aquele dos objetos manufaturados. 
Figura 3 A obra de Oliver Laric

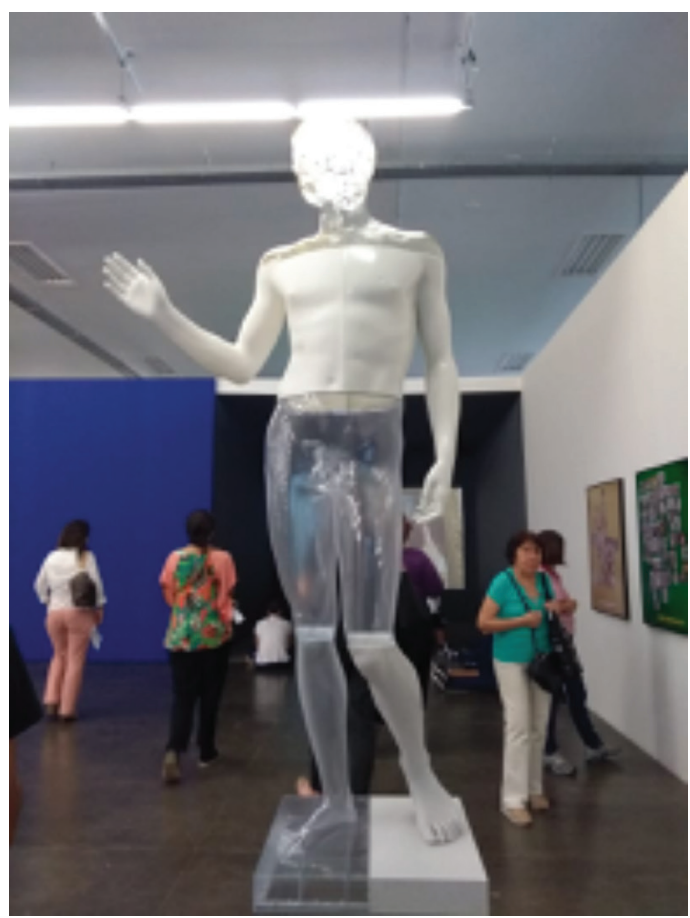

Fonte: Foto de Luisa Pinheiro.

No entanto, foi a obra de Sturtevant, que também fez parte da 33a Bienal, a que com mais intensidade pôde revelar como a noção de autoria se desloca na arte contemporânea. Em seu Duchamp in advance of the broken arm (Duchamp adiantado do braço quebrado), datado de 1992, ele reproduz o ready-made proposto por Duchamp, que esteve inclusive presente na Bienal de 1987. Fazendo novo jogo com o título, o artista retoma o mesmo objeto sem deixar de ser também autor da obra. Assim, além de poder ressignificar objetos cotidianos, 0 artista se coloca como aquele que pode também ressignificar uma outra obra de arte, criando camadas de autoria entre obras que não cessam de dialogar. 
Figura 4 Duchamp in advance of the broken arm, de Sturtevant

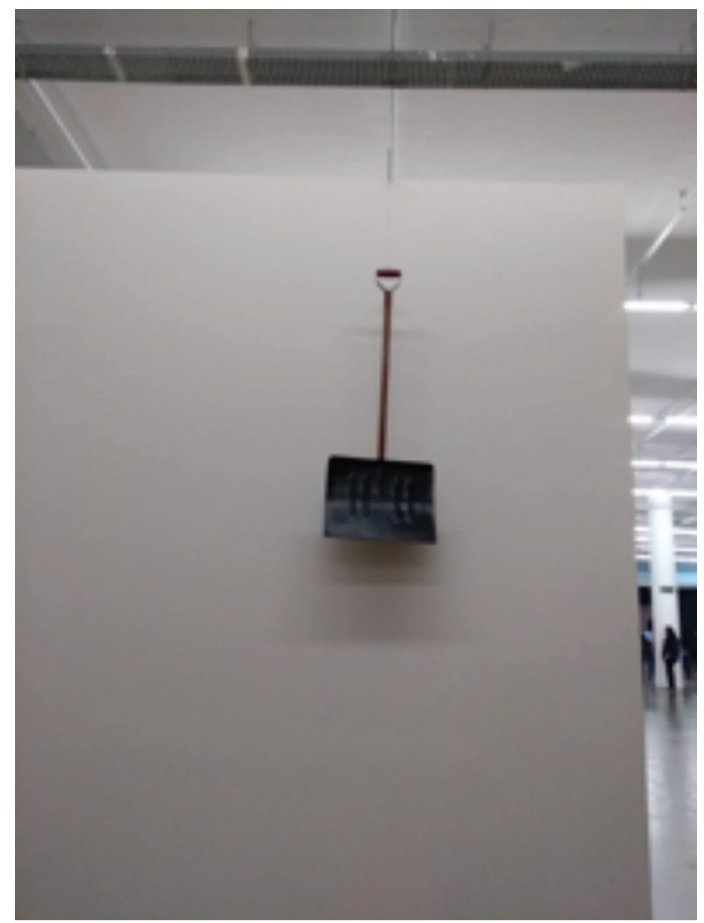

Fonte: Foto de Luísa Pinheiro.

\section{A ARTE CONTEMPORÂNEA E SUA RELAÇÃO COM OS INDIVÍDUOS E A PÓS-MODERNIDADE}

A partir de uma breve observação das exposições atuais (e também de anteriores) da Bienal, é possivel notar então que a premissa de que há uma arte contemporânea questionadora - que coloca em discussão pedras antes consideradas fundamentais para a arte, como a figura do autor e a própria conceituação do que é uma obra de arte - é verdadeira. Logo, esse olhar atento para a Bienal mostra também que tal processo é de fato um fenômeno social e cultural, por tratar-se de um grande evento, e que pode ser, por isso, analisado também historicamente, no sentido de que aponta para uma determinada sociedade, com determinados anseios e questões que, por sua vez, transbordam para o fazer artístico. Por esse motivo, para se compreender a própria arte contemporânea, é extremamente interessante se pensar um pouco sobre o determinado período histórico e filosófico em que se vive hoje, de modo a se ter, assim, uma visão mais completa da vida em sociedade.

Como dito anteriormente, a razão pela qual alguns classificam a arte contemporânea como pós-modernismo dá-se justamente por essa visão de um deslocamento radical histó- 
rico que mudou a maneira de a sociedade viver e pensar a modernidade e a pós-modernidade (ou modernidade tardia, como alguns ainda colocariam). Por isso, há uma visão da existência de um modernismo e, como consequência, um pós-modernismo. Aqui, prefere-se a expressão arte contemporânea, mais amplamente utilizada, mas ainda assim é interessante apontar para essa diferenciação: quando há um debruçar sobre o deslocamento histórico e filosófico da modernidade para a pós-modernidade, é possível compreender as razões pelas quais para os artistas, a sociedade e os individuos é tão presente e, até mesmo, potente a reflexão a respeito das questões de autoria e de obra de arte.

0 posicionamento filosófico, inclusive, já foi aqui explicitado, quando se falou da obra de Jean Baudrillard e do pensamento filosófico pós-moderno, que se foca não mais na busca pela verdade, as grandes narrativas e o fundamento, mas sim a questão da eficácia (do efeito provocado por um ato, objeto etc.). E se vê esse deslocamento na própria ciência, uma vez que os paradigmas atuais não buscam mais ser verdadeiros, mas eficazes. Isto é, um paradigma científico é considerado verdadeiro enquanto dá vazão às questões impostas naquele momento histórico e enquanto produzir tecnicamente respostas eficazes. A partir do momento em que surge algum problema que não pode ser respondido por aquele paradigma científico, busca-se então um novo. Logo, a ciência já não busca mais a Verdade (no sentido absoluto), mas paradigmas eficazes.

E o mesmo se pode notar no questionamento trazido pelos ready-mades e pela arte contemporânea. Colocam-se ali em xeque justamente os fundamentos do que seria uma obra de arte, podendo até gerar um questionamento de que tudo poderia ser arte, desde que de algum modo seja capaz de provocar efeito - mesmo que essa não seja a intenção de seu autor. Afinal, um mictório em seu local padrão dentro de uma sociedade, ou seja, em um banheiro, não produz efeito no indivíduo que o utiliza. Talvez passe até despercebido, como algo tão presente na vida cotidiana. No entanto, ao ser colocada em um museu, sendo deslocada e reinventada, a peça ( $A$ fonte) passa a gerar efeito, uma vez que o indivíduo é afetado por ela (ao se deparar com ela), e isso gera reflexão e mudança. 0 autor da obra, todavia, embora possa cunhar um conceito, já não tem mais o monopólio da significação daquela obra, isto é, deixa de ser a fonte da verdade sobre o significado da obra, já que ela, simplesmente por estar onde está, será interpretada e ressignificada pelos indivíduos afetados por ela em um processo contínuo.

E o que se quer colocar em questão no presente artigo, então, é:

- De onde vêm esses questionamentos?

- Por que se tornaram tão importantes para a arte e, como consequência, por que são tão importantes para a sociedade e para os indivíduos? 
É justamente isso que se busca compreender, para que seja possivel mostrar a conexão intensa entre arte, sociedade e filosofia. Assim, certamente haverá também uma compreensão melhor da própria contemporaneidade.

E, bem, como dito, a resposta está no deslocamento histórico da modernidade para a pós-modernidade. Em 0 mal-estar da pós-modernidade, Bauman (1997) aponta justamente na direção desse deslocamento. Descreve uma modernidade, como expressa por Freud, em que se viveu um período de segurança, em que os mal-estares modernos advinham de um mundo que dava certezas aos indivíduos, que dava segurança social e econômica, mas que permitia uma liberdade individual pequena demais. E isso vinha de uma modernidade dos projetos coletivos, em que os indivíduos se viam justamente por um prisma das grandes narrativas, da ideia de civilidade, e de que tais projetos coletivos dariam a eles a segurança necessária para uma boa vida, mesmo que isso significasse abrir mão de um pouco de liberdade. Houve, no entanto, uma mudança radical na pós-modernidade, como Bauman (1997, p. 9) nos revela:

Isto não significa dizer, porém, que os ideais de beleza, pureza e ordem que conduziram os homens e mulheres em sua viagem de descoberta moderna tenham sido abandonados, ou tenham perdido um tanto do brilho original. Agora, todavia, eles devem ser perseguidos - e realizados - através da espontaneidade, do desejo e do esforço individuais.

E esse é um marco importante, o fato de a busca pela segurança, pelo sucesso e por uma boa vida se dar agora pelo prisma do individual, pela experiência e pelo esforço individuais. Um discurso que, naturalmente, lembra as ideias do self-made man ou self-made millionaire, que são vistas com grande intensidade na cultura norte-americana, mas que já se espaIharam justamente com a explosão do neoliberalismo. E isso, naturalmente, não é uma coincidência. 0 deslocamento da modernidade para a pós-modernidade se dá justamente no processo gradual de transformação do próprio capitalismo iniciado com o fim da Segunda Guerra Mundial (1945) e que sofreu uma grande mudança no início da década de 1980 com a ascensão e explosão do pensamento neoliberal.

Afinal, tal pensamento tem como resultado a mudança da visão do indivíduo e da sociedade de um âmbito do coletivo para o individual. 0 Estado não mais é responsável por dar segurança e gerar caminhos para o individuo. 0 individuo é quem precisa encontrar sozinho esse caminho, sendo o único responsável pelo seu fracasso ou sucesso, pois é ele que se faz sozinho, e não mais o Estado ou os projetos coletivos (como o "Estado de bem-estar social"). E Bauman (p. 54) ainda revela:

A responsabilidade pela situação humana foi privatizada e os instrumentos e métodos de responsabilidade foram desregulamentados. Uma rede de categorias abrangente e univer- 
sal desintegrou-se. 0 auto-engrandecimento está tomando o lugar do aperfeiçoamento socialmente patrocinado e a auto-afirmação ocupa o lugar da responsabilidade coletiva pela exclusão de classe.

Isto é, com o advento do pensamento neoliberal e a explosão da sociedade de consumo, a vida e a experiência do indivíduo se tornam cada vez mais individualizadas e menos coletivas. E isso se vê até mesmo em hábitos de compra, em que mais vale um carro ou camiseta estilizados, para mostrar para o mundo toda a sua individualidade, do que produtos mais baratos, mas que são iguais aos demais (como se via na produção moderna de automóveis, no fordismo, com carros padronizados, em que o diferente era visto como algo negativo).

E o que isso significa? Bem, que o indivíduo passa a olhar para o mundo com outros olhos. Não mais se percebem as coisas e os acontecimentos por um prisma coletivo, faz-se isso por um prisma individual. E tal deslocamento gera uma mudança radical na percepção da própria verdade, dos fundamentos e, como consequência, da arte.

\section{CONCLUSÃO}

E como a observação da presença dos ready-mades na Bienal e o crescente questionamento da autoria e dos conceitos de obra de arte se relacionam com esse deslocamento da visão do indivíduo? Bem, é aqui que se nota a forte relação entre arte, sociedade e filosofia que se buscou trabalhar ao longo de todo o artigo.

Como já demonstrado, a arte surge muitas vezes como uma resposta a movimentos dentro da própria sociedade ou até como antecipação a eles, como, inclusive, é o caso de Duchamp e A fonte que anteciparam todo o processo histórico de mudança da modernidade para a pós-modernidade descrito até aqui. E, nesse caso, pensar por meio da arte sobre esse deslocamento de olhar para o mundo por um prisma individual e não mais coletivo é entender com muito mais facilidade as questões de esvaziamento dos fundamentos e da verdade presentes no pensamento filosófico pós-moderno.

Afinal, quando um indivíduo olha para o mundo através de uma visão individual, no momento em que se depara com uma obra de arte, ele entende que aquela obra provocou nele alguma reação. No entanto, ao mesmo tempo, por experienciar o mundo de forma individual, ele percebe que aquela é uma experiência sua, entende que aquela mesma obra pode significar algo completamente diferente para outra pessoa (ou até mesmo não ter sequer uma significação).

Ou seja, é a questão de perceber a obra como dotada de múltiplos significados e, portanto, de múltiplas verdades, pois irá interagir de maneira diferente com cada indivíduo. E isso difere radicalmente da experiência moderna, que buscaria por um significado real para aquela 
obra, o "significado verdadeiro", muitas vezes exposto pelo próprio autor. Numa visão coletiva, há essa luta pela verdade, por ter um consenso social do que é bom ou não - ou do que significa aquela obra ou não, no caso da arte.

Todavia, na sociedade contemporânea, da explosão do neoliberalismo, da sociedade de consumo e do deslocamento de uma visão de mundo coletiva para uma individual, a visão sobre a própria obra de arte, seus fundamentos e, como consequência, sua autoria, se modifica. 0 que importa são os efeitos e significados produzidos em cada indivíduo e sua capacidade de gerar múltiplos efeitos e múltiplas verdades. E isso só se torna possível por hoje se viver em um período em que essa percepção de mundo é viável.

Exatamente por isso, ao se observar a arte contemporânea e as exposições da 33a Bienal, achou-se interessante fazer essa reflexão, pois o estudo de tais obras, isto é, o estudo das razões para a constante produção de obras que questionam os próprios fundamentos da arte, revela muito sobre o próprio momento filosófico, social e histórico atual, trazendo certamente uma maior compreensão sobre os anseios e as visões do indivíduo pós-moderno. Além disso, como mencionado, explicita-se também a enorme capacidade que as obras de arte possuem de antecipar (ou criar) movimentos sociais e de também expressá-los por meio dos questionamentos que por elas são gerados.

\title{
Art, society and the importance of ready-mades in the Bienal de São Paulo
}

\begin{abstract}
This article tries to investigate why, in contemporary art, we see a greater presence of works of art that question the place of the author, as a creator, and also the fundamentals of what a work of art actually is. In order to do that, it is necessary to observe, in the the Bienal de São Paulo, the presence of the ready-mades and, doing that, try to have a better understanding about the relationship between art, society and philosophy. This will allow us to think about how the way society and also the individuals perceive art changes when we move from a society of collective projects (more predominant in the modern era) to na individual way of seeing reality (more predominant in the postmodern era).
\end{abstract}

Keywords: Contemporary art. Bienal de São Paulo. Modern. Postmodern. Postmodernism.

\section{REFERÊNCIAS}

BARTHES, R. O rumor da língua. São Paulo: Brasiliense, 1988.

BAUDRILLARD, J. Simulacros e simulação. Lisboa: Relógio d'Água, 1991.

BAUMAN, Z. O mal-estar da pós-modernidade. Rio de Janeiro: Jorge Zahar, 1997. 
BENJAMIN, W. A obra de arte na era de sua reprodutibilidade técnica. In: BENJAMIN, W. Obras escolhidas I. São Paulo: Brasiliense, 1987.

BRETON, A.; ELUARD, P. Dictionnaire abrégé du surrealisme. Paris: Librarie Jose Corti, 1938.

EAGLETON, T. As ilusões dos pós-modernismo. Rio de Janeiro: Jorge Zahar, 1996.

FOUCAULT, M. 0 que é um autor? In: FOUCAULT, M. Estética: literatura e pintura, música e cinema. Tradução Inês Barbosa. Rio de Janeiro: Forense, 2011. (Coleção Ditos \&t escritos III).

PERRONE-MOISÉS, L. Texto, crítica, escritura. São Paulo: Ática, 1993. 